\title{
Meckel's Diverticulum in Paediatric Age Group: A Spectrum of Clinical Presentations and its Management
}

\author{
Dr. Rajshekhar Patil ${ }^{1}$, Dr. Sharan Gubbi ${ }^{2}$, Dr. Karthik Dhaded ${ }^{3}$, Dr. Sanjay $K^{4 *}$
}

\author{
${ }^{1}$ Professor, Mr Medical College, Sedam Road, Mahadevappa Marg, Gulbarga, Karnataka 585105, India \\ ${ }^{2}$ Assistant Professor, Mr Medical College, Sedam Road, Mahadevappa Marg, Gulbarga, Karnataka 585105, India \\ ${ }^{3}$ Senior Resident, Mr Medical College, Sedam Road, Mahadevappa Marg, Gulbarga, Karnataka 585105, India \\ ${ }^{4}$ Post Graduate, Mr Medical College, Sedam Road, Mahadevappa Marg, Gulbarga, Karnataka 585105, India
}

DOI: $\underline{10.36347 / \text { sasjs.2020.v06i11.001 }}$

| Received: 13.10.2020 | Accepted: 26.10.2020 | Published: 05.11.2020

*Corresponding author: Sanjay K

Abstract

Original Research Article

Meckel,s Diverticulum is a true diverticulum which is seen in approximately $2 \%$ of the population. The presentation of which may range from asymptomatic to gastrointestinal bleeding to intestinal obstruction. This wide range of presentations makes it a difficult entity to diagnose. In view of this, we conducted a study between the period of Jan 2017 to Dec 2017 including all suspected cases of Meckel's Diverticulum, in order to study the various modes of presentation, the intraoperative management and the postoperative outcome. In our study, out of a total of 14 patients, 6 patients presented with intestinal obstruction, 3 patients with peritonitis, 2 patients were suspected to have appendicitis and in 3 patients, Meckel's Diverticulum was an incidental finding. In all the above patients, wedge resection of the Diverticulum was performed.

Keywords: Meckel's Diverticulum, diverticulitis, paediatric Meckel's.

Copyright () 2020 The Author(s): This is an open-access article distributed under the terms of the Creative Commons Attribution 4.0 International License (CC BY-NC 4.0) which permits unrestricted use, distribution, and reproduction in any medium for non-commercial use provided the original author and source are credited.

\section{INTRODUCTION}

Meckel's diverticulum was first described in a paper published in 1809 by the German anatomist, Johann Friedrich Meckel, the younger (1781-1833), who described it as a remnant of the omphalomesenteric duct [1], However, it was not until almost 100 years later that the understanding of Meckel ${ }^{\text {le }} \mathrm{s}$ diverticulum increased with the discovery of ectopic gastric mucosas by Salzer and associated ulceration of ileum by Deetz [2]. In the fetal life, the omphalomesenteric duct connects the yolk sac to the intestinal tract and usually it obliterates in the 5th to 7 th week of life. If obliteration fails, the congenital anomalies develop, leading to the residual fibrous cords, umbilical sinus, omphalo-mesenteric fistula, enterocyst and most commonly, Meckel's diverticulum. It represents the patent intestinal end of the vitello intestinal duct. It possesses all three coats of intestine. In $20 \%$ of the cases the mucosa contains heterotopic gastric, colonic, or pancreatic tissue. It presents in $2 \%$ of the population at a ratio of three male to one female. Its usual location is $30-60 \mathrm{~cm}$ from ileocecal valve. The presence of this heterotopic tissue may lead to other complications like haemorrhage, chronic peptic ulceration, and perforation. It generally remains silent but it may present with life threatening complications like intestinal obstruction, perforation, haemorrhage [3], etc. These complications present with nonspecific symptoms which mimic common gastrointestinal disorders [4] like appendicitis, making it difficult to diagnose. Most of the cases are diagnosed intraoperatively.

Meckel's diverticulum is a true diverticulum containing all layers; it is usually situated on the antimesentric border, approximately seen in $2 \%$ of population. Most patients are asymptomatic and the life time risk of developing the complications is 4-6\% [5]. Gastrointestinal bleeding is the most common complication in adults and the second most in children; it is due to presence of heterotopic gastric or pancreatic mucosa causing ulceration of adjacent ileal mucosa. Obstruction due to Meckel's diverticulum is the most common complication in children and second most common complication in adults [6]. Obstruction is due to volvulus or intussusception or Littre's hernia or adhesion and kinking or due to stricture secondary to chronic diverticulitis [7]. Complications of Meckel's diverticulum include haemorrhage, obstruction, diverticulitis and perforation and technetium $99 \mathrm{~m}$ pertechnetate scan is used for diagnosis which is highly sensitive and specific in both paediatric and adult population $[7,8]$. Other diagnostic modalities include capsule endoscopy and angiography. If conservative 
methods fail to control haemorrhage diverticulectomy or ileal segment resection with end to end anastomosis are done. Perforation is due to diverticulitis or ulceration due to heterotopic mucosa or rarely due to foreign body (like fish bone, chicken bone, etc.).

Treatment of perforation is segmental resection with end to end anastomosis. Pathophysiology of diverticulitis is similar to that of acute appendicitis, with inflammation secondary to stasis (due to fecolith or parasites or foreign body) and bacterial infection [8, 9]. It may also result from heterotopic mucosa. Usually, treatment is diverticulectomy.

\section{AIM}

To study the various modes of presentation of Meckel's Diverticulum, the intraoperative management and the post-operative outcome.

\section{MATERIALS AND METHODS}

A Retrospective study of all cases of Meckel's Diverticulum was conducted, that were diagnosed intraoperatively during the period of Jan 2017 to Dec
2017 in Basaveshwar Teaching and General Hospital, Kalaburagi.

No. of cases: 14

\section{Inclusion Criteria}

- $\quad$ Age $<14$ yrs

- All cases with Meckel's Diverticulum identified intra-operatively.

\section{Exclusion Criteria}

- Suspected cases of Meckel's Diverticulum, with no identifiable Meckel's Diverticulum intra-operatively.

All the cases were studied for their mode of presentation, intraoperative findings and post-operative outcome and complications.

\section{RESULTS}

This study included 14 cases

\begin{tabular}{|l|l|l|l|}
\hline AGE (in years) & NUMBER OF PATIENTS & MALE & FEMALE \\
\hline$<1$ & 5 & 4 & 1 \\
\hline $1-3$ & 5 & 4 & 1 \\
\hline $3-14$ & 4 & 2 & 2 \\
\hline TOTAL & 14 & 10 & 4 \\
\hline
\end{tabular}

In this study, there were $10(71.4 \%)$ male patients and $4(28.5 \%)$ female patients.

Male: Female ratio $=2.5: 1$

Mode of Presentation

\begin{tabular}{|l|l|}
\hline MODE OF PRESENTATION OF MECKEL'S DIVERTICULITIS & NUMBER OF PATIENTS \\
\hline Intestinal obstruction & 6 \\
\hline Peritonitis & 3 \\
\hline Ac. Appendicitis & 2 \\
\hline Incidental & 3 \\
\hline Total & 14 \\
\hline
\end{tabular}

All patients underwent exploratory laparotomy with right supraumbilical transverse skin crease incision. In patients with suspected appendicitis, McBurney's Gridiron incision was taken.

All 6 patients who presented with symptoms of Intestinal Obstruction underwent surgery after attempting conservative management for 12 hours. All the 6 patients were noted to have Meckel's Diverticulum with band that formed a loop around a segment of ileum leading to obstruction. In 3 of these patients, there were multiple adhesions between the bowel loops and therefore, along with wedge resection, adhesiolysis was done. In 1 case, the patient also had a patent urachus connecting to the bowel. The urachus was cut and sutured in 2 layers following wedge resection of Meckel's Diverticulum. In 1 of these patients, the segment of Ileum between the band was gangrenous and therefore, resection and anastomosis was performed. In 1 patient, stricture was noted $\sim 5 \mathrm{~cm}$ from IC junction and therefore resection and anastomosis was done.

Out of the 3 patients who presented with features of peritonitis: 2 patients were found to have gangrenous Meckel's diverticulum and underwent wedge resection of the Diverticulum. 1 patient was found to have Meckel's band with perforation of Ileum. Patient underwent wedge resection of Meckel's Diverticulum with perforation closure.

Both the patients who were diagnosed to have appendicitis were noted to have normal appendix intraop and therefore Meckel's Diverticulum was looked for and diverticulitis was confirmed and resection done. 
In 3 patients, Meckel's diverticulum was incidentally noted as the patients were being operated for appendectomy, ileal and jejunal perforations respectively.
The Meckel's Diverticulum was not inflamed and had wide base in all the cases; however a decision to perform wedge resection was taken in all the cases after the primary disease was addressed.

Intra-Operative Findings

\begin{tabular}{|l|l|}
\hline FINDINGS & NUMBER OF PATIENTS \\
\hline Meckel's band & 6 \\
\hline Meckel's band with intestinal perforation & 1 \\
\hline Gangrenous Meckel's Diverticulum & 2 \\
\hline Meckel's Diverticulitis & 2 \\
\hline Incidentally noted Meckel's Diverticulum (with no signs of inflammation or ischaemia) & 3 \\
\hline Total & 14 \\
\hline
\end{tabular}

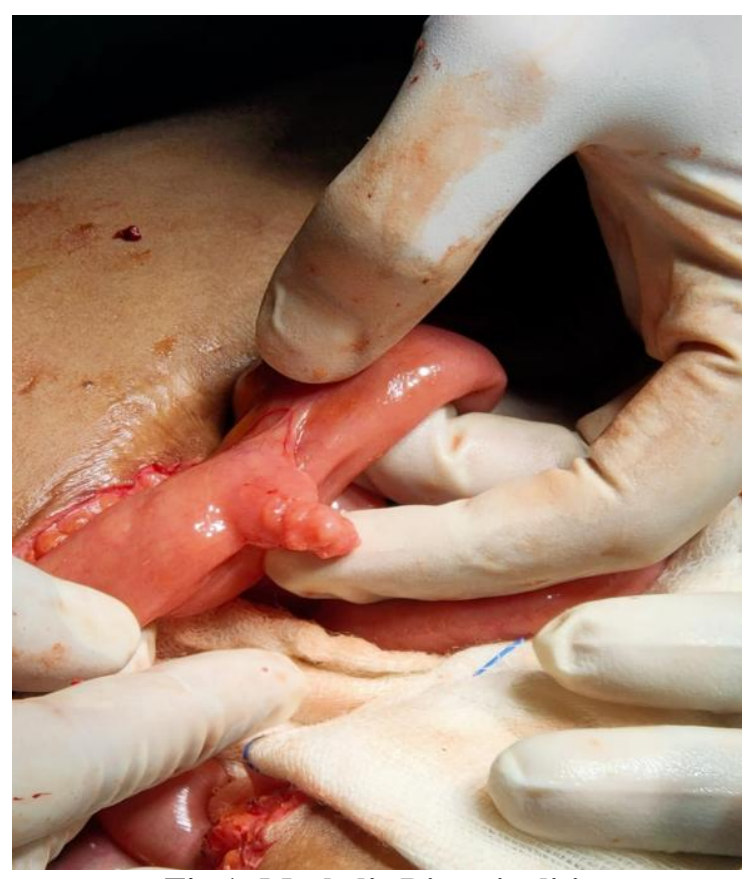

Fig 1: Meckel's Diverticulitis

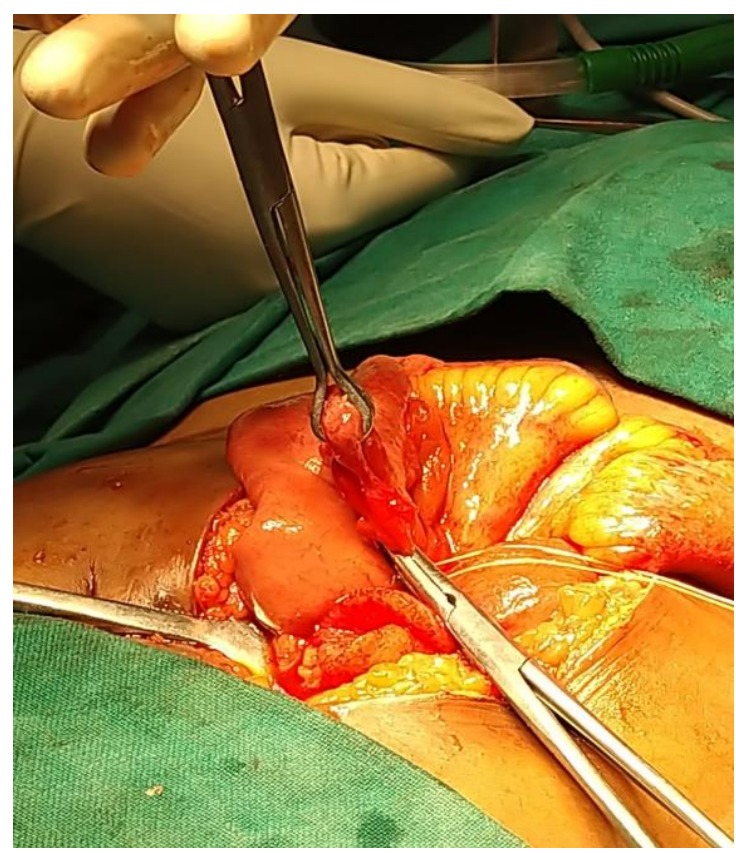

Fig-2: Meckel's Band

\section{DISCUSSION}

In our study, out of a total of 14 patients, there was a male preponderance with 10 male and 4 female patients and a male to female ratio of $2.5: 1$, which is consistent with the study conducted by Ruscher KA et al., [10]. 10 (71.42\%) of our patients were under the age of $3 y r s$, with the youngest patient being 11 days old and the oldest being $14 \mathrm{yrs}$ of age.

The most common mode of presentation in this study was intestinal obstruction, seen in $6(42.85 \%)$ patients. This finding is also consistent with various other studies $[5,11,12]$. All the cases were due to formation of Meckel's band and the severity of the obstruction ranged from formation of adhesions between the involved bowel loops to gangrenous changes of the involved segment. In one case, even stricture at the site of obstruction was seen.

In our study, 2 (14.28\%) patients were noted to have Meckel's Diverticulitis, aged 7 yrs and 12 yrs. Both the patients presented to us clinically as appendicitis but intraoperatively appendices appeared normal and, on exploration, were found to have Meckel's Diverticulitis. Wedge resection of such cases is mandated as the incidence of peritonitis is known to be higher in a case of a perforated Meckel's Diverticulum than perforated appendix as the diverticuli are freely mobile within the peritoneal cavity [13]. This incidence is also in common with various studies reported $[5,11,12]$.

Although gastrointestinal bleeding is known to be one of the most common modes of presentation in paediatric age group with an incidence as high as 50\% reported in some studies [14], there were no such cases noted in our study.

In addition to the above, we also incidentally noted $3(21.43 \%)$ cases of Meckel's diverticulum, in patients undergoing abdominal surgery for other conditions. In all these cases, a decision to perform wedge resection of Meckel's Diverticulum was taken. Although it is known that a large number of patients would require resection of an incidental Meckel's Diverticulum in order to prevent one death due to Meckel's Diverticulum [15], there still persists a 
dilemma on whether or not to resect an incidentally noted Meckel's Diverticulum.

\section{CONCLUSION}

As Meckel's Diverticulum is notorious in its presentation, a definite pre-operative diagnosis is a challenge. Even a thorough clinical exam and efficient radiological studies do not come to aid. Hence, most often the diagnosis is made intraoperatively.

It is therefore imperative to consider Meckel's Diverticulum as one of the differential diagnosis for cases presenting with intestinal obstruction, perforation peritonitis and suspected cases of appendicitis.

Although the discussion still continues, on whether an incidentally identified asymptomatic Meckel's Diverticulum needs resection.

\section{REFERENCES}

1. Meckel JF. Uber die divertikel am darmkanal. Arch Physiol. 1809; 9:421-53.

2. Stone PA, Hofeldt MJ, Lohan JA, Kessel JW, Flaherty SK. A rare case of massive gastrointestinal haemorrhage caused by Meckel ${ }^{\text {ee }} \mathrm{s}$ diverticulum in a 53-year-old man. W V Med J 2005;101:64-6.

3. Kuwajerwala NK, Silva YJ. Meckels diverticulum. eMed J 2002;3:7.

4. Yahchouchy EK, Marano AF, Etienne JC, Fingerhut AL. Meckel ${ }^{\text {ee }}$ s diverticulum. J Am Coll Surg. 2001;192:658-62.

5. Raymond P. Adjunctive procedure in intestinal surgery. Mastery of Surgery. 5th ed. Wolters Kulwer Health/Lippincott Williams \& Wilkins: Philadelphia; 2007. 1392-3.

6. Peranteau WH, Smink DS. Appendix, Meckel's and other Small Bowel Diverticula: Maingot's
Abdominal Operations. 12th ed. New York: McGraw Hill Professional; 2013. p. 643-4.

7. Horn F, Trnka J, Simicková M, Duchaj B, Makaiová I. Symptomatic Meckel's diverticulum in children. Rozhl Chir 2007;86:480-2.

8. Sagar J, Kumar V, Shah DK. Meckel's diverticulum: A systematic review. J R Soc Med 2006;99:501 -5.

9. Chirdan LB, Yusufu LM, Ameh EA, Shehu SM. Meckel's diverticulitis due to Taenia saginata: Case report. East Afr Med J. 2001; 78:107-8.

10. Ruscher KA, Fisher JN, Hughes CD, Neff S, Lerer TJ, Hight DW, Bourque MECKEL'S DIVERTICULUM, Campbell BT. National trends in the surgical management of Meckel's diverticulum. J Pediatr Surg. 2011 May;46(5):8936.

11. Bazrafshan A, Heydarian F, Rahmani S. Meckel's diverticulum: Prevalence in 1000 laparatomies. Patient Saf Qual Improv. 2013;1:10-2.

12. Oguzkurt P, Talim B, Tanyel FC, Caglar M, Senocak ME, Büyükpamukçu N. The role of heterotopic gastric mucosa with or without colonization of Helicobacter pylori upon the diverse symptomatology of Meckel's diverticulum in children. Turk J Pediatr. 2001;43:312-6.

13. Rattan KN, Singh J, Dalal P, Rattan A. Meckel's diverticulum in children: Our 12-year experience. African journal of paediatric surgery: AJPS. 2016 Oct;13(4):170.

14. Ur Rehman I, Burki T, Alam S, e Rahman F. Presentations of Meckel's diverticulum at Khyber Teaching Hospital Peshawar. J Ayub Med Coll Abbottabad. 2003;15:30-2.

15. Zani A, Eaton S, Rees CM, Pierro A. Incidentally detected Meckel diverticulum: to resect or not to resect? Ann Surg. 2008 Feb;247(2):276-81. 